\title{
PENGARUH EFIKASI DIRI DAN PENDIDIKAN KEWIRAUSAHAAN TERHADAP MINAT WIRAUSAHA MAHASISWA PENDIDIKAN EKONOMI UNIVERSITAS PANCA SAKTI
}

\author{
Eka Putri \\ Universitas Panca Sakti, Bekasi, Indonesia \\ ekaputri@panca-sakti.ac.id
}

$\begin{array}{ll}\text { Received: } & 15 \text { April } 2021 \\ \text { Revised: } & 11 \text { Agustus } 2021 \\ \text { Accepted: } & 16 \text { Agustus } 2021\end{array}$

\begin{abstract}
This study aims to determine the effect of self-efficacy and entrepreneurship education on interest in entrepreneurship. The research was conducted on students of Economics Education Class of 2019 who have completed the Entrepreneurship Education course. This research uses the associative quantitative method with a series of instrument tests and classical assumption tests. The sample in this study were 52 people. The sampling technique was done randomly. The type of data used is primary data, then the data is analyzed using partial t-test and F-test. Based on the results of data analysis, the results of the study can be concluded as follows: (1). Self-efficacy of students of the economic education study program at Panca Sakti University in Bekasi does not significantly affect the interest in entrepreneurship. (2). Entrepreneurship education for students of the Economic Education study program at the Panca Sakti University in Bekasi has a significant effect on interest in entrepreneurship. (3). Self-efficacy and entrepreneurship education together have an effect on the entrepreneurial interest of students in the economic education study program at Panca Sakti University Bekasi
\end{abstract}

Keywords: Self-Efficacy, Entrepreneurship Education, Interest In Entrepreneurship

(*) Corresponding Author: $\quad$ Putri, ekaputri@panca-sakti.ac.id, +62 82172240859

How to Cite: Putri, E. (2021). Pengaruh Efikasi Diri Dan Pendidikan Kewirausahaan Terhadap Minat Wirausaha Mahasiswa Pendidikan Ekonomi Universitas Panca Sakti. Research and Development Journal of Education, 7 (2), 269-278.

\section{INTRODUCTION}

Pengangguran merupakan masalah klasik yang sampai sekarang di upayakan penyelesaiannya oleh pemerintah. Kesenjangan ketersediaan lapangan pekerjaan dengan jumlah Angkatan kerja, kurangnya kompetensi tenaga kerja dan banyaknya jumlah penduduk sudah menjadi factor klasik penyebab terjadinya masalah pengangguran tersebut. Pada awal tahun 2020, masalah penganguran tidak lagi hanya di sebabkan oleh factor klasik saja tetapi muncul masalah baru yaitu pandemic Covid-19 yang mengakibatkan banyak tenaga kerja yang kehilangan pekerjaan. Badan Pusat Statistik (2021) mengungkapkan bahwa pada Februari Tahun 2021 jumlah angkatan kerja indonesia sebanyak 139,81 juta orang terdiri dari 131,06 juta orang yang bekerja dan 8,75 juta pengangguran. Terdapat 19,10 juta orang terkena Covid-19, dimana 9,30 persen adalah Angkatan kerja yang menganggur karena Covid-19 sebanyak 1.62 juta, sementara tidak bekerja karena Covid-19 sebanyak 1.11 juta dan yang jam kerjanya di kurangi sebanyak 15, 72 juta orang. Berdasarkan data yang ada dapat diketahui bahwa tingkat pengangguran tidak hanya dari tenaga kerja yang tidak bekerja atau yang sedang mencari pekerjaan namun juga dari tenaga kerja yang kehilangan pekerjaan karena terdampak covid-19. Selain itu Indonesia juga memiliki tingkat wirausaha yang rendah jika dibandingkan dengan negara-negara tetangga seperti Singapura, Malaysia, dan Thailand. 
Pada tahun 2021, Menteri BUMN menyebutkan bahwa jumlah entrepeneur Indonesia baru sekitar 3,47\% dari jumlah penduduk. Jumlah ini dibawah jumlah wirausaha negara Malaysia dan Thailand yang sudah sebanyak $4,74 \%$ dan $4,26 \%$. Sedangkan singapura sudah mencapai $8.76 \%$.

Untuk mengatasi masalah diatas, mahasiswa sebagai generasi penerus terdidik yang nantinya ditakutkan turut menjadi penyumbang angka pengangguran diharapkan mampu merubah kondisi diatas dengan merubah pandangan dari pencari kerja menjadi pencipta lapangan pekerjaan dengan berwirausaha. Untuk mengembangkan minat berwiraausaha seseorang perlu memantapkan keyakinan pada dirinya bahwa ia mampu untuk melakukan hal tersebut (Self-Eficacy). Menurut Bandura (dalam Dewi \& Mugiarso, 2020) efikasi diri merupakan keyakinan seseorang akan kemampuan yang dimiliki dalam melakukan control terhadap fungsi dirinya dan kejadian dilingkungannya. Teori bandura ini dapat digambarkan sebagai berikut:

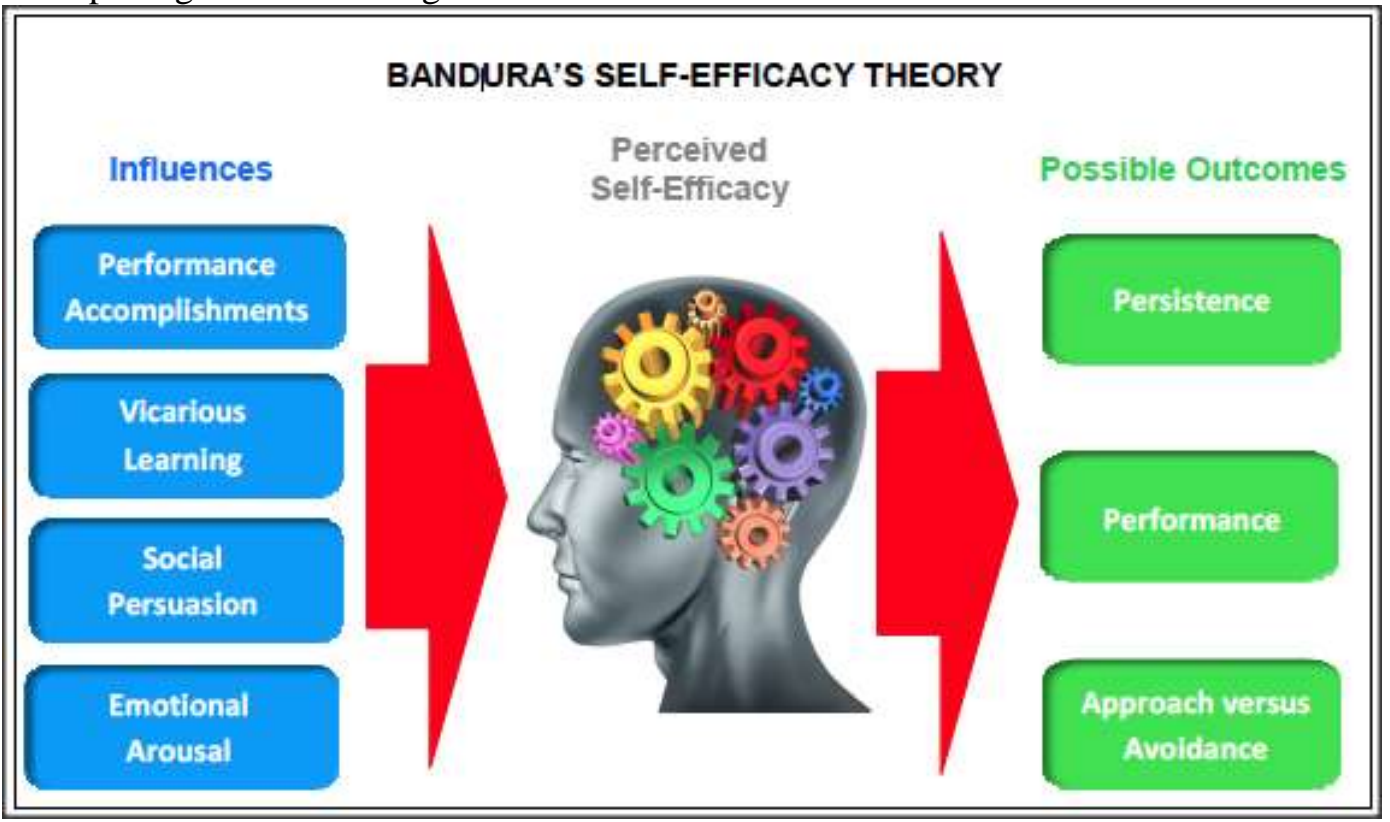

Gambar 1.

Uji Normalitas

Sumber: Teori Bandura

Keyakinan akan diri manusia berbeda tergantung pada manusia tersebut, bisa keyakinan dalam hal baik ataupun keyakinan dalam hal buruk. Azwar (2012) menambahkan bahwa jika seorang manusia berkayakinan untuk melakukan perbuatan baik, maka manusia tersebut akan berusaha sebaik mungkin untuk melakukan hal tersebut. Keyakinan pada diri sendiri juga akan membawa kesuksesan usaha seperti yang disebutkan oleh Dessyana dan Riyanti (2017) bahwa proses entrepreneur bukanlah sesuatu yang mudah di jalankan sehingga di butuhkan entrepreneur self eficasi untuk mendorong suksesnya usaha. Triwardhani dan Nobelson (2014) juga menyebutkan bahwa self eficasi memiliki pengaruh positif terhadap minat berwirausaha.

Selain dibutuhkan efikasi diri yang mantap, pendidikan kewirausahaan juga diperlukan dalam menumbuhkan minat berwirausaha dikalangan mahasiswa terutama mahasiswa pendidikan ekonomi yang tidak hanya dipersiapkan menjadi tenaga pendidik dibidang ekonomi namun juga diharapkan memiliki kemampuan berwirausaha yang kreatif dan inovatif. Menurut Wibowo (2011:30) Pendidikan kewirausahaan adalah suatu upaya penerapan jiwa dan mental wirausaha melalui lembaga pendidikan maupun lembaga lain seperti pelatihan dan sebagainya. Pemberiaan materi pada saat perkuliahan 
kewirausahaan diharapkan bisa menjadi bekal mahasiswa untuk memulai usaha dan mampu membuat peluang kerja bagi orang lain nantinya. Pemerintah juga memberikan peluang pada mahasiswa untuk mengembangkan jiwa wirausahanya dengan mengadakan kegiatan pelatihan yang bekerja sama dengan kampus seperti program mahasiswa berwirausaha dan program kreativitas mahasiswa dengan tujuan untuk membangun dan memotivasi mahasiswa untuk berwirausaha. Penelitian Putri (2017) menunjukkan variabel Pendidikan kewirausahan memberikan pengaruh signifikan positif terhadap minat mahasiswa berwirausaha. Turker dan Selcuk (2009) juga menjelaskan bahwa jika pihak kampus memberikan dukungan berupa bekal pengetahuan kewirausahaan maka minat berwirausaha mahasiswa akan meningkat. Jadi diperlukan Pendidikan kewirausahaan untuk menumbuhkan minat berwirausaha mahasiswa.

Peneliti melakukan observasi awal pada mahasiswa Pendidikan ekonomi Universitas Panca Sakti Bekasi yang telah mengambil mata kuliah Pendidikan kewirausahaan mengenai minat berwirausaha. Hasil observasi yang dilakukan secara acak menunjukkan bahwa mahasiswa yang menempuh mata kuliah kewirausahaan diambil dari beberapa program reguler menunjukkan bahwa mahasiswa telah bekerja diberbagai bidang namun masih minim yang berwirausaha karna sebagaian besar mahasiswa bekerja di Instansi dan lembaga pemerintah dibanding memulai usaha sendiri. Fenomena lain yang di temukan adalah masih ada beberapa mahasiswa yang tidak dapat menangkap peluang usaha, terdapat beberapa mahasiswa yang mau memulai membuka usaha namun kurang motivasi, kurangnya keberanian untuk memulai usaha, dan modal yang kurang memadai. Hal tersebut di atas menunjukkan minat berwirausaha serta keyakinan pada diri sendiri yang masih rendah. Cahyaning (dalam Hendrawan \& Sirine, 2017) berpendapat minat wirausaha merupakan keinginan dari dalam diri seseorang yang berjiwa berani untuk menciptakan suatu usaha agar sukses untuk hidup lebih baik. Berdasarkan uraian diatas penulis tertarik untuk mengkaji lebih lanjut mengenai Efikasi Diri, Pendidikan Kewirausahaan dan Minat wirausaha pada Mahasiswa Pendidikan Ekonomi Univeritas Panca Sakti Bekasi.

\section{LITERATURE REVIEW}

\section{Efikasi Diri}

Menurut Bandura (dalam Dewi \& Mugiarso, 2020) efikasi diri merupakan keyakinan seseorang akan kemampuan yang dimiliki dalam melakukan control terhadap fungsi dirinya dan kejadian dilingkungannya. Bandura juga menambahkan bahwa efikasi diri adalah penentu bagaimana sesorang merasa, berfikir, bersikap dan memotivasi diri sendiri. Senada dengan Feist \& Feist (dalam Saraswati \& Dewi Piartini, 2017) yang berpendapat efikasi diri adalah keyakinan seseorang bahwa ia memiliki kemampuan dalam mengontrol pekerjaannya dan peristiwa di lingkungannya. Baron \& Byrne (dalam Saraswati \& Dewi Piartini, 2017) menyebutkan bahwa efikasi diri adalah penilaian seseorang terhadap kemampuannya dalam melakukan sesuatu tugas, mencapai tujuan dan menghasilkan sesuatu. self-efficacy mengacu pada persepsi kepercayaan seseorang pada kemampuan untuk melakukan suatu aktivitas melalui empat sumber yang mempengaruhi self-efficacy yaitu simpati atau motivasi dari seseorang, pengalaman, pencapaian kinerja, serta psikologis dan emosional (Anggresta, Stevani, Vhalery, \& Oktasari, 2019)

\section{Pendidikan Kewirausahaan}

Pendidikan kewirausahaan adalah suatu upaya penerapan mental dan jiwa kewirausahaan melalui lembaga pendidikan maupun Lembaga lain seperti lembaga 
pelatihan dan sebagainya (Wibowo, 2011:30). Lestari \& Wijaya (Dalam Wibowo \& Pramudana, 2016) menyebutkan pendidikan kewirausahaan tidak hanya memberikan teori konsep kewirausahaan saja tetapi juga pembentukan sikap, perilaku dan mindset entrepreneur. Keat et al (Dalam Wibowo \& Pramudana, 2016) juga menambahkan bahwa tujuan utama dalam Pendidikan kewirausahaan yaitu merubah pandangan, pola perilaku dan minat seseorang tentang kewirausahan sehingga kelak bisa menjadi wirausaha sukses dan mampu membuka lapangan pekerjaan baru bagi orang lain.

\section{Minat Wirausaha}

Rahmadi \& Heryanto (2016) menjelaskan minat wirausaha merupakan kecenderunagan hati seseorang yang tertarik untuk melakukan suatu usaha dengan mengelola, mengatur, menanggung resiko dan berusaha mengembangkan usaha tersebut. Cahyaning (dalam Hendrawan \& Sirine, 2017) berpendapat minat wirausaha merupakan keinginan dari dalam diri seseorang yang berjiwa berani untuk menciptakan suatu usaha agar sukses untuk hidup lebih baik. Suryana (2014) juga menambahkan minat berwirausaha merupakan pilihan seseorang yang muncul karena adanya ketertarikan dan keberanian untuk mengambil resiko dalam berusaha.

\section{METHODS}

Penelitian ini menggunakan penelitian kuantitatif asosiatif dengan serangkaian uji instrumen dan uji asumsi klasik. Data yang di pakai adalah data primer. Populasi dalam penelitian ini adalah mahasiswa prodi Pendidikan ekonomi Angkatan 2019 sebanyak 109 orang yang telah menyelesaikan mata kuliah Pendidikan kewirausahaan. Teknik pengambilan sampel dilakukan secara random (random sampling). Untuk mengetahui jumlah sampel peneliti menggunakan rumus slovin dengan persentase kelonggaran yang digunakan yaitu $10 \%$. Maka diperoleh sampel sebanyak 52 orang. Teknik penumpulan data menggunakan kuesioner, observasi dan studi pustaka. Teknik analisis data penelitian menggunakan analisis regresi linear berganda untuk melihat pengaruh variabel bebas terhadap variabel terikat.

\section{RESULTS \& DISCUSSION}

\section{Uji Asumsi Klasik}

\section{a. Uji Normalitas}

Uji Normalitas dalam penelitian ini menggunakan uji Normalitas Probability Plot seperti Gambar 1 berikut: 


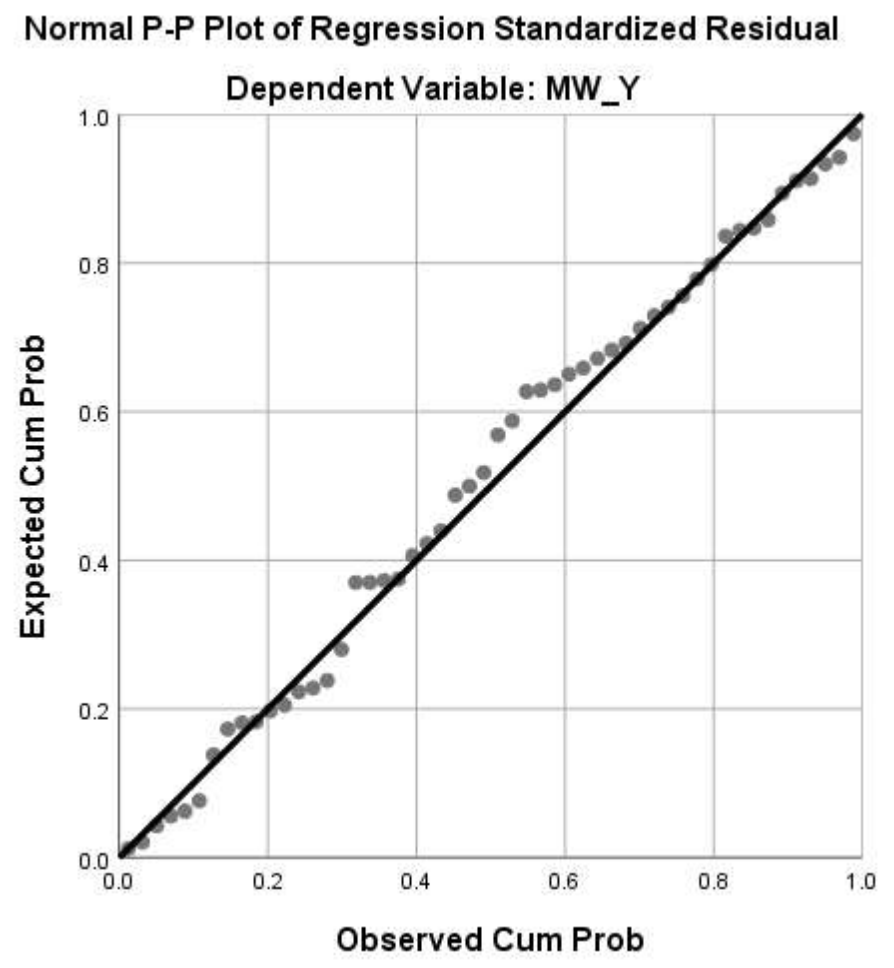

Gambar 2.

Uji Normalitas

Sumber: Data Olahan Peneliti (2021)

Berdasarkan Gambar 2 di atas terlihat bahwa data ploting (titik-titik) mengikuti garis diagonal maka dapat di simpulkan bahwa data terdistribusi Normal. Hal ini sesuai dangan Ghozali (2011:161) menyatakan bahwa model regresi dikatakan berdistribusi normal jika data ploting (titik-titik) mengikuti garis diagonal.

\section{b. Uji Multikolinieritas}

Uji Multikolinieritas menggunakan Uji Multikolinieritas Tolerance danVIF seperti tabel 1 berikut:

Tabel 1.

Uji Multikolinieritas

\begin{tabular}{|c|c|c|c|c|c|c|c|}
\hline \multirow{2}{*}{ Model } & \multicolumn{2}{|c|}{$\begin{array}{l}\text { Unstandardized } \\
\text { Coefficients }\end{array}$} & \multirow{2}{*}{$\begin{array}{c}\text { Standardized } \\
\text { Coefficients } \\
\text { Beta }\end{array}$} & \multirow{2}{*}{$\mathbf{T}$} & \multirow{2}{*}{ Sig. } & \multicolumn{2}{|c|}{$\begin{array}{l}\text { Collinearity } \\
\text { Statistics }\end{array}$} \\
\hline & B & \begin{tabular}{|c|} 
Std. \\
Error
\end{tabular} & & & & Tolerance & VIF \\
\hline (Constant) & -2.824 & 7.318 & & -.386 & .701 & & \\
\hline ED_X1 & .323 & .175 & .194 & 1.847 & .071 & .917 & 1.091 \\
\hline PW_X2 & 1.309 & .218 & .630 & 6.005 & .000 & .917 & 1.091 \\
\hline
\end{tabular}

Sumber: Data Olahan Peneliti (2021)

Pada tabel 1 terlihat bahwa nilai tolerance $0.917>0.100$ dan nilai VIF < 10.00 hal ini berarti tidak ada gejala Multikolinieritas sesuai dgn Ghozali (2011:107-108) Tidak terjadi gejala multikolinieritas jika nilai tolerance $>0.100$ 
dan nilai VIF $<$ 10.00. Artinya dalam model regresi tidak ada korelasi antar variabel independent atau variabel bebas.

\section{c. Uji Heteroskedastisitas}

Untuk menguji Heteroskedastisitas, peneliti menggunakan uji scatterplots seperti Gambar 2 berikut:

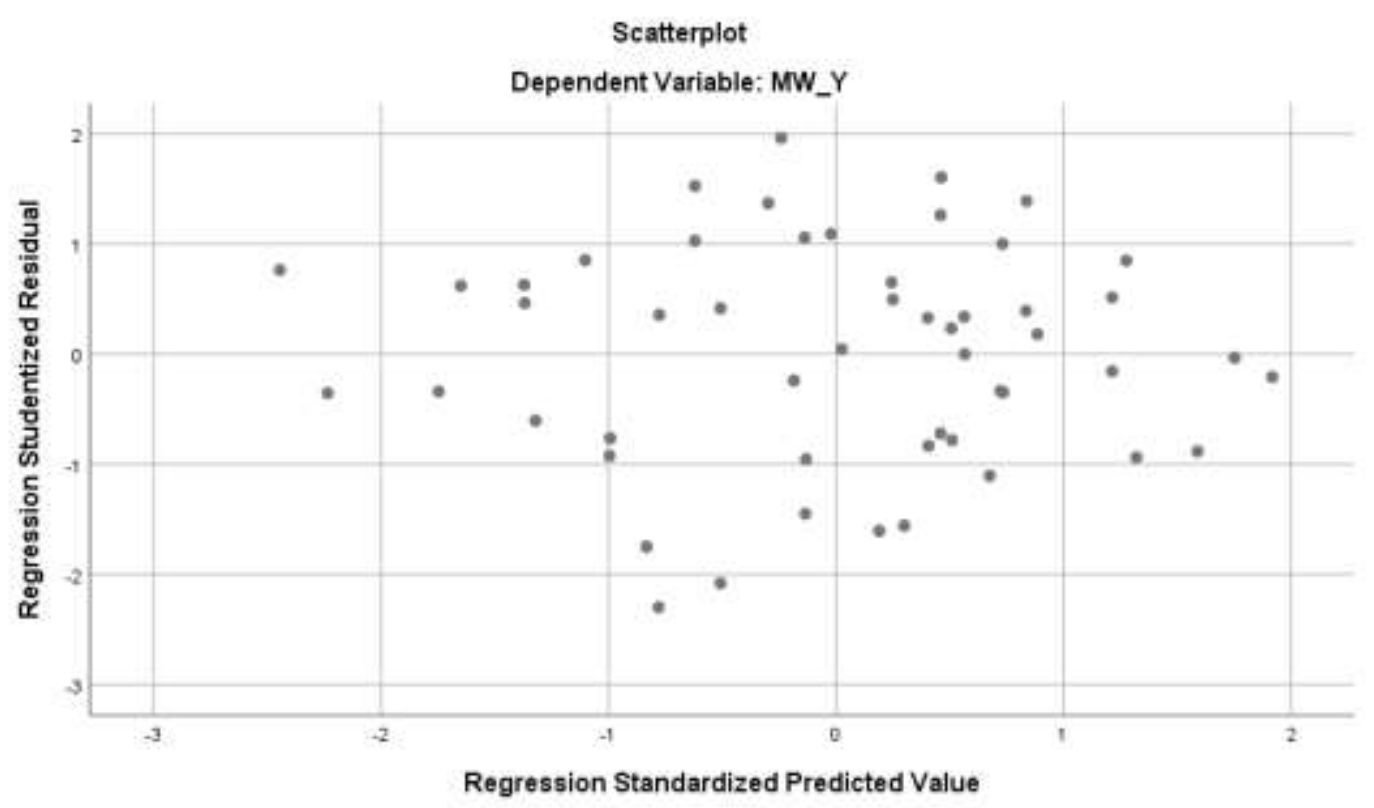

Gambar 3

Uji Heteroskedastisitas

Sumber: Data Olahan Peneliti (2021)

Pada Gambar 3 diatas terlihat bahwa titik-titik menyebar secara acak, gambar pola tidak terlihat jelas serta titik-titik di atas dan di bawah angka 0 pada sumbu Y maka di simpulkan bahwa tidak adanya gejala heteroskedastisitas. Sesuai dgn pendapat Ghozali (2011:139) menyatakan bahwa jika pola tidak menunjukkan kejelasan (bergelombang, menyebar kemudian menyempit) pada gambar scatterplots, serta titik menyebar di bawah dan di atas angka 0 pada sumbu Y maka tidak adanya gejala heteroskedastisitas.

\section{d. Uji Autokorelasi}

Uji autokorelasi menggunakan Uji Autokorelasi Durbin Watson seperti tabel 2 di bawah ini:

Tabel 2.

Uji Autokorelasi

\begin{tabular}{lc|c|c|c|l}
\hline Model $\quad \mathbf{R}$ & $\begin{array}{c}\mathbf{R} \\
\text { Square }\end{array}$ & $\begin{array}{c}\text { Adjusted R } \\
\text { Square }\end{array}$ & $\begin{array}{c}\text { Std. Error of the } \\
\text { Estimate }\end{array}$ & Durbin-Watson \\
\hline 1 & $.711^{\mathrm{a}}$ & \multicolumn{5}{l|}{.505} & .485 & 6.121 & 1.641 \\
\hline \multicolumn{3}{l}{ Sumber: Data Olahan Peneliti (2021) }
\end{tabular}

Berdasarkan Tabel 2 di atas dapat diketahui bahwa nilai Durbin Watson adalah 1.641. Untuk mengetahui apakah terdapat gejala autokorelasi dalam model regresi, Gozhali (2011: 111) menyebutkan bahwa tidak ada gejala autokorelasi jika nilai durbin Watson terletak antara DU sampai dengan (4-DU). Nilai DU dicari berdasarkan nilai $\mathrm{K}$ (jumlah variabel independent) dan nilai $\mathrm{N}$ dalam tabel Durbin 
Watson pada signifikansi $5 \%$. Maka di peroleh nilai DU $=(1.6334)<$ Durbin Watson (1.641) < 4-DU (2.3666). Artinya nilai DU lebih kecil dibanding dengan nilai Durbin Watson dan nilai Durbin Watson berada antara DU dan 4-DU. Maka disimpulkan bahwa tidak ada gejala autokorelasi.

\section{Uji Regresi Lenier Berganda}

\section{a. Uji t Parsial}

Untuk melihat pengaruh masing-masing variabel independent terhadap variabel dependent menggunakan Uji t Parsial dengan signifikansi kesalahan 5\% atau 0.05. Jika nilai sig > 0.05 maka artinya variabel independent secara parsial berpengaruh terhadap variabel dependent. Hasil perhitungan Uji t Parsial dapat dilihat pada tabel 3 berikut:

Tabel 3.

Uji t Parsial

\begin{tabular}{|c|c|c|c|c|c|c|c|}
\hline \multirow[t]{2}{*}{ Model } & \multicolumn{2}{|c|}{$\begin{array}{l}\text { Unstandardized } \\
\text { Coefficients }\end{array}$} & \multirow{2}{*}{$\begin{array}{c}\text { Standardized } \\
\text { Coefficients } \\
\text { Beta }\end{array}$} & \multirow[t]{2}{*}{$\mathbf{T}$} & \multirow[t]{2}{*}{ Sig. } & \multicolumn{2}{|c|}{$\begin{array}{l}\text { Collinearity } \\
\text { Statistics }\end{array}$} \\
\hline & B & Std. Error & & & & Tolerance & VIF \\
\hline (Constant) & -2.824 & 7.318 & & -.386 & .701 & & \\
\hline ED_X1 & .323 & .175 & .194 & 1.847 & .071 & .917 & 1.091 \\
\hline PW_X2 & 1.309 & .218 & .630 & 6.005 & .000 & .917 & 1.091 \\
\hline
\end{tabular}

Sumber: Data Olahan Peneliti (2021)

Dari tabel 3 diatas terlihat bahwa nilai signifikansi variabel Efikasi diri sebesar $0.71>0.05$ artinya variabel efikasi diri tidak berpengaruh pada minat berwirausaha mahasiswa prodi Pendidikan ekonomi. Nilai signifikansi variabel Pendidikan kewirausahaan sebesar $0.00<0.05$ artinya variabel Pendidikan wirausaha mempengaruhi minat berwirausaha mahasiswa Pendidikan ekonomi.

b. Uji F

Uji $\mathrm{F}$ di gunakan untuk mengetahui apakah terdapat pengaruh secara simultan dari semua variabel independent terhadap variabel dependent. Menurut Ghozali (2011:101) jika nilai sig < 0.05 maka variabel independent akan berpengaruh terhadap variabel dependent.

Tabel 4.

Uji F

\begin{tabular}{lc|c|c|c|c}
\hline \multicolumn{1}{c}{ Model } & Sum of Squares & Df & Mean Square & F & Sig. \\
\hline Regression & 1875.124 & 2 & 937.562 & 25.028 & $.000^{\mathrm{b}}$ \\
\hline Residual & 1835.568 & 49 & 37.461 & & \\
\hline Total & 3710.692 & 51 & & & \\
\hline
\end{tabular}

Sumber: Data Olahan Peneliti (2021)

Dari tabel 4 di atas terlihat nilai sig $0.000<0.05$ yang berarti efikasi diri dan pendidikan kewirausahaan mempengaruhi minat berwirausaha mahasiswa pendidikan ekonomi. Berdasarkan hasil uji t parsial terlihat bahwa nilai signifikansi variabel Efikasi diri sebesar $0.71>0.05$ artinya variabel efikasi diri tidak berpengaruh pada minat berwirausaha mahasiswa Pendidikan ekonomi universitas panca sakti.

Maka dapat di simpulkan bahwa $\mathrm{H}_{\mathrm{a} 1}$ di tolak yang artinya efikasi diri tidak berpengaruh terhadap minat berwirausaha. Hasil ini di dukung oleh hasil penelitian 
Aje (2019) yang juga menunjukkan bahwa efikasi diri tidak berpengaruh secara terhadap minat berwirausaha. Hal ini menunjukkan bahwa tingkat keyakinan pada diri sendiri mahasiswa Pendidikan ekonomi universitas panca sakti Bekasi dalam berwirausaha masih rendah.

Pada variabel Pendidikan kewirausahaan Nilai signifikansi $0.00<0.05$ artinya variabel Pendidikan wirausaha berpengaruh terhadap minat wirausaha mahasiswa pendidikan ekonomi universitas panca sakti secara signifikan. Maka dapat di simpulkan bahwa $\mathrm{H}_{1}$ di diterima yang artinya Pendidikan kewirausahaan berpengaruh signifikan terhadap minat berwirausahan. Hasil penelitian ini didukung oleh hasil penelitian Aje (2019) yang menyatakan bahwa Pendidikan wirausaha berpengaruh signifikan terhadap minat berwirausaha. Senada dengan Hasil penelitian Putri (2017) menunjukkan bahwa Pendidikan kewirausahan menberikan pengaruh positif terhadap minat mahasiswa berwirausaha. Hal ini menunjukkan bahwa Pendidikan dan pengetahuan yang di peroleh mahasiswa selama perkuliahan dinilai dapat meningkatkan minat berwirausaha mahasiswa Pendidikan ekonomi universitas panca sakti, Bekasi. Jika Pendidikan kewirausahaan mahasiswa di tingkatkan satu satuan maka minat berwirausaha mahasiswa juga akan meningkat satu satuan. Pendidikan yang di peroleh mahasiswa selama perkuliahan bisa di jadikan bekal oleh mahasiswa nantinya untuk membuka usaha. Hal ini didukung dengan pendapat Nurhalimah (2017) yang menyatakan bahwa pendidikan dan pengetahuan yang di peroleh selama kuliah adalah modal besar yang dapat di gunakan mahasiswan untuk berwiraswasta, termasuk keterampilan yang di peroleh pada mata kuliah praktek.

Berdasarkan hasil uji $\mathrm{F}$ di ketahui nilai sig $0.000<0.05$ artinya variabel Pendidikan wirausaha dan efikasi diri berpengaruh terhadap minat wirausaha mahasiswa Pendidikan ekonomi universitas panca sakti. Dapat disimpulkan bahwa penolakan pada $\mathrm{H}_{0}$ dan penerimaan pada $\mathrm{H}_{a 1}$. Hasil penelitian ini didukung hasil penelitian relevan oleh Aje (2019) yang menyatakan bahwa efikasi diri dan Pendidikan kewirausahaan memiliki korelasi secara Bersama-sama terhadap minat berwirausaha. Hasil penelitian ini sejalan dengan hasil penelitian yang dikemukakan oleh Kirana (2018), yang mengungkapkan bahwa terdapat pengaruh positif dan signifikan antara efikasi diri dan pendidikan kewirausahaan pada minat berwirausaha.

\section{CONCLUSION}

1. Efikasi diri mahasiswa pendidikan ekonomi universitas panca sakti Bekasi tidak berpengaruh terhadap minat berwirausaha. Hal ini dilihat dari hasil Uji t Parsial yang menunjukkan nilai signifikansi variabel efikasi diri sebesar $0.71>0.05$. Nilai signifikansi variabel efikasi diri lebih besar dari 0.05 yaitu 0.71 . Hal ini menunjukkan bahwa tingkat keyakinan pada diri sendiri mahasiswa prodi Pendidikan ekonomi universitas panca sakti Bekasi dalam berwirausaha masih rendah.

2. Pendidikan kewirausahaan mahasiswa Pendidikan ekonomi universitas panca sakti Bekasi berpengaruh secara signifikan terhadap minat berwirausaha. Hal ini dilihat dari hasil Uji $\mathrm{t}$ Parsial yang menunjukkan nilai signifikansi variabel Pendidikan kewirausahan sebesar $0.00<0.05$. artinya Pendidikan dan pengetahuan yang di peroleh mahasiswa selama perkuliahan dinilai dapat meningkatkan minat mahasiswa berwirausaha. 
3. Adanya pengaruh bersama antara efikasi diri dan Pendidikan kewirausahaan terhadap minat berwirausaha mahasiswa Pendidikan ekonomi universitas panca sakti Bekasi. Hal ini di lihat dari hasil Uji F yang menunnjukkan nilai signifikansi $0.000<0.05$.

\section{REFERENCES}

Aje, A. U., dkk. (2019). Pengaruh Efikasi Diri dan Pendidikan Kewirausahaan Terhadap Minat Berwirausaha Mahasiswa Fakultas Keguruan Dan Ilmu Pendidikan Tahun Akademik 2018/2019 Universitas Flores Ende, NTT. Jurnal ilmiah manajemen.

Anggresta, V., Stevani, H., Vhalery, R., \& Oktasari, M. (2019). Jurnal Inovasi Pendidikan Ekonomi. Jurnal Inovasi Pendidikan Ekonomi, 9(1).

Azwar, S. (2012). Efikasi Diri dan Prestasi Belajar Statistik Pada Mahasiswa. Jurnal Psikologi.

Badan Pusat Statistik. (2021). Keadaan Ketenagakerjaan Indonesia Februari 2021. Jakarta: BPS.

Dessyana, A. \& Riyanti, B. P. D. (2017). The influence of innovation and entreprenurial self efficacy to digital startup success. International Research Journal of Business Studies.

Dewi, Yolanda Puspita \& Mugiarso, Heru. (2020). Hubungan Antara Konsep Diri Dengan Efikasi Diri Dalam Memecahkan Masalah Melalui Konseling Individual di SMK Hidayah Semarang. Jurnal Bimbingan Konseling.

Gozhali Imam. (2011). Aplikasi Analisis Multivariate Dengan Program IMB SPSS 19. Semarah. Badan Penerbit Undip.

Hendrawan, Josia Sanchaya \& Sirine, Hani. (2017). Pengaruh Sikap Mandiri, Motivasi, Pengetahuan Kewirausahaan Terhadap Minat Berwirausaha. Asian Journal of Innovation And Entrepreneurship.

Kirana, D. G. C, dkk. (2018). Pengaruh Pendidikan Kewirausahaan dan Self Efficacy Terhadap Minat Berwirausaha: Studi Pada Mahasiswa Program Studi Pendidikan Ekonomi Tahun Angkatan 2014-2016. Jurnal Pendidikan Bisnis dan Ekonomi. Vol 4 No 1.

Nurhalimah. (2017). Pengaruh Pengetahuan Kewirausahaan, Faktor Keluarga dan Faktor Kepribadian Terhadap Minat Berwirausaha pada Mahasiswa Manajemen Konsentrasi Kewirausahaan S-I Manajemen Fakultas Ekonomi dan Bisnis Universitas Sumatera Utara. Skripsi Universitas Sumatera Utara.

Puteri, H. E. (2012). Propose entrepreneurship's education based field trainingin islamic college (PTAI): Design strategy to create competitiveoutput. Annual International Conference on Islamic Studies (AICIS) XII.

Rahmadi, Afif Nur \& Heryanto, Budi. (2016). Analisis Faktor-faktor yang Mempengaruhi Minat Berwirausaha Pada Mahasiswa Program Studi Manajemen Fakultas Ekonomi Universitas Kadiri. Vol.1 No.2 September 2016, pp.153-169

Saraswati \& Dewi Piartini. (2017). Pengaruh Efikasi Diri Terhadap Kinerja Dengan Dukungan Organisasional Sebagai Pemoderasi. Jurnal Ekonomi dan Bisnis Universitas Udayana.

Suryana. (2014). Kewirausahaan. Jakarta: Salemba Empat.

Triwardhani, D. \& Nobelson. (2014). Intensi Kewirausahaan Mahasiswa: Perbandingan Antara Fakultas Ekonomi, Fakultas Teknik dan Fakultas Hukum UPN Veteran Jakarta.

Turker, D. \& Selcuk, S. S. (2009). Which factors affect entrepreneurial intention of university student. Journal of European Industrial Training. 
Wibowo \& Pramudana. (2016). Pengaruh Pendidikan Kewirausahaan Terhadap Intensi Berwirausaha Yang Dimediasi Oleh Sikap Berwirausaha. Jurnal Manajemen Unud.

Wibowo, A. (2011). Pendidikan Kewirausahaan: Konsep dan Strategi.Yogyakarta: Pustaka Pelajar. 